\title{
The Progression of Alzheimer's Disease: Are Fast Decliners Really Fast? A Four-Year Follow-Up
}

\author{
Federica Barocco $^{\mathrm{a}}$, Marco Spallazzi ${ }^{\mathrm{a}}$, Letizia Concari ${ }^{\mathrm{b}}$, Simona Gardini ${ }^{\mathrm{c}}$, Annalisa Pelosi $^{\mathrm{d}}$ \\ and Paolo Caffarra ${ }^{\text {a,* }}$

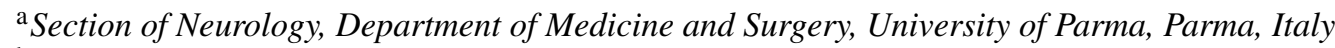 \\ ${ }^{\mathrm{b}}$ ULSS 9, Ca' Foncello Hospital, Treviso, Italy \\ ${ }^{\mathrm{c}}$ Azienda Ospedaliero-Universitaria, Parma, Italy \\ ${ }^{\mathrm{d}}$ Section of Psychology, Department of Medicine and Surgery, University of Parma, Parma, Italy
}

Accepted 5 February 2017

\begin{abstract}
.
Background: The rate of cognitive and functional decline in Alzheimer's disease (AD) changes across individuals. Objectives: Our purpose was to assess whether the concept of "fast decline" really fits its definition and whether cognitive and functional variables at onset can predict the progression of $\mathrm{AD}$.

Methods: 324 AD patients were included. We retrospectively examined their Mini-Mental State Examination (MMSE) total score and sub-items, Activities of Daily Living (ADL), and Instrumental Activities of Daily Living (IADL) at baseline and every six months for a 4-year follow-up. Patients were divided into "fast decliners" $(n=62)$, defined by a loss $\geq 5$ points on the MMSE score within the first year from the baseline; "intermediate decliners" ( $n=37)$, by a loss $\geq 5$ points after the first year and before the 18th month; or "slow decliners" $(n=225)$, composed of the remaining patients.

Results: At baseline, the groups did not differ on demographic, clinical, and cognitive variables. The decline at the end of the 4-year follow-up period seems to be similar among the different decline clusters. Predictors of disease progression have not been identified; only the MMSE total score at 12 months $<14 / 30$ was indicative of a poor prognosis.

Conclusions: Even with the limitation due to the small sample size, the lack of differences in the disease progression in time in the different clusters suggest the inconsistency of the so-called "fast decliners". This study was unable to show any significant difference among clusters of $\mathrm{AD}$ progression within a 4-year time interval. Further studies should better clarify whether a more consistent distinction exists between slow and fast decliners.
\end{abstract}

Keywords: Alzheimer's disease, cognitive predictors, dementia progression, fast decliners, Mini-Mental State Examination

\section{INTRODUCTION}

Progressive cognitive and functional decline over the course of the disease is the main characteristic of Alzheimer's disease (AD). However, the rate of progression is variable among individuals with some patients presenting the classical form characterized

\footnotetext{
*Correspondence to: Caffarra Paolo, MD, Department of Medicine and Surgery, University of Parma, Via Gramsci, 14, 43100 Parma, Italy. Tel./Fax: +39 0521 704116; E-mail: paolo.caffarra@unipr.it.
}

by a slower decline, such as mean decline of 2-3 MiniMental State Examination (MMSE) points/year [1], and others with a more rapid decline. Although this phenomenon is well known, no comprehensive studies are available explaining the relationship between the clinical phenotype and the biological variables implicated in modulating the course of the disease. In a recent multicenter study where genetic properties, cerebrospinal fluid biomarkers (CSF), neuropathology, and clinical features were examined, $A P O E$ $\varepsilon 4$ homozygosity was absent and CSF biomarkers 
Table 1

Comorbidity factors in Alzheimer's disease progression

\begin{tabular}{|c|c|c|c|}
\hline & Source & $\begin{array}{l}\text { Influence on rate } \\
\text { of decline }\end{array}$ & Ref \\
\hline \multirow[t]{3}{*}{ Vascular risk factors } & Blom et al., 2013; Blom et al., 2014 & unclear & {$[41,42]$} \\
\hline & Abellan van Kan et al., 2009 & $=$ & [3] \\
\hline & Roselli et al., 2009 & $>$ & [5] \\
\hline Hypertension & Musicco et al., 2009 & $=$ & [9] \\
\hline \multirow[t]{2}{*}{ Hypercholesterolemia } & $\begin{array}{l}\text { Abellan van Kan et al., 2009; Musicco et al., 2009; Sakurai } \\
\text { et al., 2011; Li et al., 2010; Li et al., 2008; Ciobica et al., } 2011\end{array}$ & $=$ & {$[3,9,44-47]$} \\
\hline & Helzner et al., 2009; Li et al., 2008 & > (only LDL) & {$[4,46]$} \\
\hline \multirow[t]{3}{*}{ Diabetes Mellitus } & $\begin{array}{l}\text { Dominguez et al., 2012; Ravona-Springer et al., 2010; Sanz } \\
\text { et al., 2009; Musicco et al., 2009; Mielke et al., 2007 }\end{array}$ & $<$ & {$[6-9,48]$} \\
\hline & Helzner et al., 2009; Li et al., 2010 & $>$ & {$[4,45]$} \\
\hline & $\begin{array}{l}\text { Abellan van Kan et al., 2009; Sakurai et al., 2011; Chaves et al., } \\
\text { 2010; Bhargava et al., } 2006 \text { 2009; van Bruchem-Visser et al., } \\
\text { 2009; Regan et al., } 2006\end{array}$ & 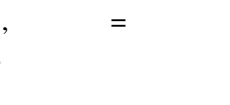 & {$[3,44,49-52]$} \\
\hline \multirow[t]{2}{*}{ Obesity } & Abellan van Kan et al., 2009; Li et al., 2010 & $=$ & {$[3,45]$} \\
\hline & Dumont et al., 2003 & $>$ & [27] \\
\hline Smoke & $\begin{array}{l}\text { Bhargava et al., 2006; van Bruchem-Visser et al., 2009; Regan } \\
\text { et al., } 2006\end{array}$ & $=$ & {$[50-52]$} \\
\hline \multirow[t]{3}{*}{ High educational level } & $\begin{array}{l}\text { Roselli et al., 2009; Musicco et al., 2009; Musicco et al., 2010; } \\
\text { Teri et al., 1995; Scarmeas et al., } 2006\end{array}$ & $>$ & {$[5,9,10,53,54]$} \\
\hline & Pavlik et al., 2006 & $<$ & {$[55]$} \\
\hline & Marra et al., 2000; Kinkingnéhun et al., 2008 & $=$ & {$[11,14]$} \\
\hline Low education & Musicco et al., 2009 & $<$ & [9] \\
\hline \multirow[t]{2}{*}{ Low age of onset } & $\begin{array}{l}\text { Musicco et al., 2009; Musicco et al., 2010; Buccione et al., } \\
\text { 2007; O’Hara et al., 2002; Teri et al., 1995; Mungas et al., } \\
2009\end{array}$ & $>$ & {$[9,10,23,24,53,56]$} \\
\hline & $\begin{array}{l}\text { Boller et al., 1991; Kinkingnéhun et al., 2008; Stern et al., } \\
\text { 1994; Burns et al., 1991; Haupt et al., } 1992\end{array}$ & $=$ & {$[12,14,16,17,57]$} \\
\hline Higher age of onset & Nyth et al., 1991; Carcaillon et al., 2007 & $>$ & {$[13,22]$} \\
\hline \multirow{7}{*}{ BPSD } & Teri et al., 1995 & $>$ (agitation) & [53] \\
\hline & Wilkosz et al., 2010 & $>$ & [25] \\
\hline & Drachman et al., 1990 & $=$ & {$[15]$} \\
\hline & Mangone et al., 2004 & $>$ & [58] \\
\hline & Palmer et al., 2011 & $>$ (disinhibition) & [26] \\
\hline & Wilkosz et al., 2010 & $>$ & [25] \\
\hline & Starkstein et al., 2006 & > (apathy) & [59] \\
\hline $\begin{array}{l}\text { Moderate-severe } \\
\text { cognitive decline at } \\
\text { baseline }\end{array}$ & $\begin{array}{l}\text { Morris et al., 1993; Musicco et al., 2010; Marra et al., 2000; } \\
\text { Burns et al., 1991; Sona et al., 2012; Carcaillon et al., 2007; } \\
\text { Buccione et al., 2007; Dumont et al., 2003; Ito et al., } 2010 .\end{array}$ & $>$ & {$[1,10,11,17,21-23,27,60]$} \\
\hline \multirow[t]{4}{*}{ Cognitive Deficits } & $\begin{array}{l}\text { Musicco et al., 2010; Marra et al., 2000; Buccione et al., 2007; } \\
\text { O'Hara et al., 2002; Mann et al., } 1992\end{array}$ & $>$ (executive $)$ & {$[10,11,23,24,61]$} \\
\hline & Kinkingnéhun et al., 2008 & $>$ (attention) & [14] \\
\hline & Smith et al., 2001 & $>$ (apraxia) & [62] \\
\hline & Burns et al., 1991 & $=($ apraxia/aphasia $)$ & {$[17]$} \\
\hline Lower ADL at baseline & Sona et al., 2012 & $>$ & [21] \\
\hline \multirow[t]{3}{*}{ Neurological signs } & Schmidt et al., 2010 & $>$ & [63] \\
\hline & Mangone et al., 2004; Scarmeas et al., 2005 & $>$ (motor signs $)$ & {$[58,64]$} \\
\hline & Drachman et al., 1990 & $=($ extrapir. signs $)$ & {$[15]$} \\
\hline \multirow[t]{2}{*}{ AChEI assumption } & Sona et al., 2012; Carcaillon et al., 2007 & $>$ & {$[21,22]$} \\
\hline & Roselli et al., 2009 & $<$ & [5] \\
\hline \multirow[t]{2}{*}{ Sex } & $\begin{array}{l}\text { Kinkingnéhun et al., 2008; Drachman et al., 1990; Stern et al., } \\
1994\end{array}$ & $=$ & [14-16] \\
\hline & Roselli et al., 2009 & $>$ (male) & [5] \\
\hline \multirow[t]{2}{*}{ Familiarity for dementia } & Drachman et al., 1990; Stern et al., 1994 & $=$ & {$[15,16]$} \\
\hline & Burns et al., 1991 & $>$ & [17] \\
\hline \multirow{3}{*}{$\begin{array}{l}\text { Genetic Biomarkers } \\
\text { (ApoE E4) }\end{array}$} & Cosentino et al., 2008; Craft et al., 1998 & $>$ & {$[65,66]$} \\
\hline & Wilkosz et al., 2010; Kester et al., 2009 & $=$ & {$[25]$} \\
\hline & Van der Viles et al., 2009 & $<$ & [67] \\
\hline
\end{tabular}

$>$, increases; <, reduction; =, unchanged; ADL, Activities of Daily Living; AChEI, acetylcholinesterase inhibitors; BPSD, behavioral and psychological symptoms of dementia. 
were abnormal as expected for classic $\mathrm{AD}$, with the exception for proteins 14-3-3, which were present in $42 \%$ [2]. Contradictory results are also evident considering the influence of comorbidities on AD progression, such as cardiovascular disease [3-5], diabetes [5-9], educational level [5, 9-11], age of disease onset [9, 12, 13], gender [5, 14], and family history of dementia [15-17]. In particular, diabetes mellitus, which is thought to modulate the risk of AD $[18,19]$, may increase or decrease the speed of progression of AD. A prognostic value has also been assigned to clinical features, such as the decline of MMSE score, in the progression time interval before diagnosis [20] or the severity of cognitive impairment at the onset of dementia [10,11, 21-24], the presence of behavioral and mood disorders [25-27], or neurological signs such as extrapyramidal signs or myoclonus $[15,28]$, but no definite conclusions have been reached (see Table 1). Moreover, many other factors have been suggested to influence the rate of progression of the disease such as cognitive reserve [29], medical and social care [30], chronic drug assumption $[5,21,22,31]$, genetics (carrying the ApoE $\varepsilon 4$ genotype) [2, 25], and environmental conditions $[32,33]$. Furthermore, it should be observed that different methods of assessment and follow-up time intervals used in these studies might act as misleading factors.

A crucial point on this topic relies on the definition of "fast decliners" suggesting a lack of general consensus on this term. In many studies, the rate of attainment of some endpoints such as institutionalization [34, 35], death [22], and the cognitive and functional worsening have been measured by different scales, preferentially the MMSE. Very heterogeneous were also the criteria used to intercept patients with rapid cognitive decline according to the length of time interval. In most of the studies, the follow-up time ranges from 3 to 12 months with one exception to 36 months, thus making it difficult to reach a firm conclusion (see Table 2).

Using the MMSE, a different approach has been proposed by Marra et al. The authors defined fast decliners as those patients whose percentage of the MMSE score's reduction was greater than $25 \%$ per year as compared to the first examination [11]. A different method was used by Doody et al. who classified rapid progressor patients with a loss of $\geq 5$ MMSE points per year [20], while for Buccione et al., fast cognitive decliners were those patients whose MMSE differential score fell above or below the overall sample median [23].
Table 2

Definition of "fast decline" based on MMSE score point decrement on time

\begin{tabular}{lcc}
\hline Source & $\begin{array}{c}\text { MMSE score point decrement/ } \\
\text { time of observation }\end{array}$ & Ref \\
\hline Kinkingnéhun et al., 2008 & $\geq 6 / 36$ months & {$[14]$} \\
Sona et al., 2012 & $\geq 6$ /first 18 months & {$[21]$} \\
Soto et al., 2008 & $\geq 4 /$ first 6 months & {$[68]$} \\
Soto et al., 2005 & $\geq 4 / 6$ months plus $\geq 1 /$ & {$[69]$} \\
& 6 months follow up \\
Soto et al., 2008 & $\geq 3 / 6$ months & {$[70]$} \\
Dumont et al., 2003 & $\geq 3 / 6$ months & {$[27]$} \\
O'Hara et al., 2002 & $\geq 3 / 12$ months & {$[24]$} \\
Carcaillon et al., 2007 & $\geq 3 / 12$ months & {$[22]$} \\
Doody et al., 2001 & $\geq 5 / 12$ months & {$[20]$} \\
Schmidt et al., 2011 & $\geq 6 / 12$ months & {$[71]$} \\
\hline
\end{tabular}

Although there is an unclear scenario on the definition of the term of fast decline, the identification of patients at higher risk for a rapid disease progression could help clinicians and families in planning a timely intervention for care. Thus, there is a need for cognitive and functional markers able to early detect the rate of decline in $\mathrm{AD}$ patients.

The purpose of this study was to assess the longitudinal reliability of an early AD patient stratification, based on the reduction of MMSE performance. We investigated whether the definition of fast decliners is of value to establish with certainty a poor prognosis in terms of cognitive and functional decline. Using a large sample of patients and a long follow-up (4 years), we examined whether a rapid decline within the first 12 or 18 months from the baseline assessment identifies worst cognitive performances at the end of follow-up. Furthermore, given the presence of controversial results in the literature, we aimed to assess whether the demographic profile and the presence of comorbidities could interfere with the progression of $\mathrm{AD}$.

\section{MATERIALS AND METHODS}

\section{Participants}

A total of 846 patients consecutively admitted to the Center of Cognitive Disorders, AUSL, Parma, Italy, between October 2009 and October 2010 entered the study. 458 patients had probable AD, 107 had mild cognitive impairment, 144 had other diagnoses (possible $\mathrm{AD}$, frontotemporal dementia, Lewy body dementia, vascular dementia, Parkinson's disease or atypical parkinsonisms, psychiatric disorders, hydrocephalus), and 137 patients performed in the normal range (see Fig. 1). Among the 458 


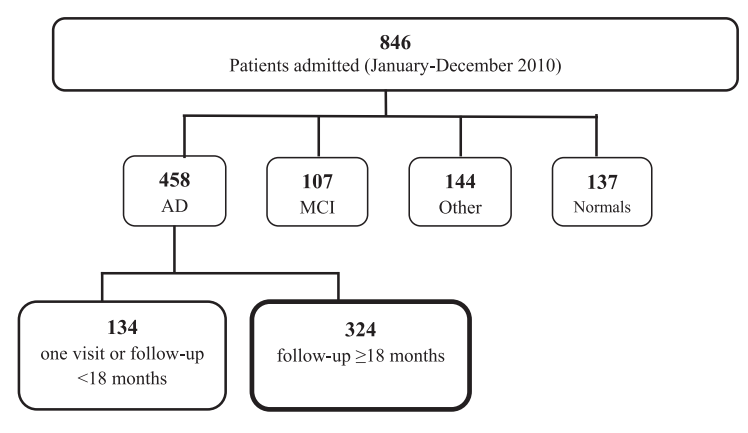

Fig. 1. Study population. AD, Alzheimer's disease; MCI, mild cognitive impairment.

patients with $\mathrm{AD}, 134$ had only one assessment or had a follow-up $<18$ months and were not included in the study; the remaining 324 patients ( 254 females, 70 males; mean age $77.3 \pm 6.5$; mean education $5.5 \pm 2.9)$ were selected for the study and retrospectively examined.

\section{Procedures}

All the patients were examined by a neurologist or geriatrician expert in cognitive disorders. The diagnosis of dementia and AD were made according to DSM-IV [36] and NINCDS-ADRDA criteria [37] by the examiner. All demographic (age, sex, education) and clinically relevant information (familiar history of dementia; age at the onset of symptoms; drug treatments: antihypertensive, antiaggregant, anticoagulant, statins, acetylcholinesterase inhibitors, memantine, and antipsychotic; and comorbidities: alcohol, smoke, hypertension, diabetes, dyslipidemia, folic acid or cobalamin deficit, hypothyroidism, anemia, cardiac, renal or hepatic failure, cerebral stroke, myocardial infarction, atrial fibrillation, epilepsy, and depression) were collected from the patient and his/her caregiver. At the time of the first visit and at each 6-month follow-up examination, cognitive impairment was assessed by the MMSE [38]; functional level was assessed by Activities of Daily Living (ADL) and Instrumental Activities of Daily Living (IADL) [39]. At baseline evaluation, patients were also submitted to a neuropsychological battery focusing on language, memory, visuo-spatial, executive, and praxic abilities.

\section{Disease progression}

According to the literature, we chose a 5-point MMSE score decrease as the threshold indicative of a clinically relevant and rapid progression $[1,20,40]$.
On the basis of the clinical observation, many patients deteriorated rapidly within 12 months, while others were found to have a recovery phase or a plateau after 12 months taking into account the difference of the actual MMSE global score compared to the score at baseline.

The MMSE score was used to assign patients to the Fast Decliners (FD; $n=62$ ) when the MMSE score loss was equal or more than 5 points at $T_{12}$ versus $T_{0}$ or Intermediate Decliners (ID; $n=37$ ) when the loss was equal or more than 5 points at $\mathrm{T}_{18}$ versus $\mathrm{T}_{0}$; the remaining subjects were classified as Slow Decliners (SD; $n=225)$.

At the end of the 4-year follow-up, $121 \mathrm{SD}, 15$ ID, and 20 FD completed the follow-up clinical observation.

\section{Statistical analysis}

All statistical analyses were performed using SPSS software version 19. Differences in baseline variables between groups were assessed using the one-way analysis of variance (ANOVA) and pair-wise Bonferroni post-hoc test. Statistical differences in categorical variables were analyzed by Pearson's chi square test. We used polynomial trend analysis to describe rates of cognitive decline in the three groups. We performed ROC analysis to find a MMSE threshold able to correctly predict the persistence of the patients into their own group at the last follow-up visits.

\section{RESULTS}

No between groups significant differences (see Table 3) at baseline on demographic (gender, age, education, familiar history of dementia), clinical (alcohol intake, smoke, hypertension, diabetes, dyslipidemia, folic acid or cobalamin deficit, hypothyroidism, anaemia, cardiac, renal or hepatic failure, cerebral stroke, myocardial infarction, atrial fibrillation, epilepsy, depression), functional (ADL) and cognitive (MMSE) variables were found, except for the IADL score which were significantly higher in SD than in FD (Bonferroni post-hoc test: $p<0.05$, means differences $95 \% \mathrm{CI}=-1.71--0.16$ ). There were no significant differences between groups on drugs assumption.

\section{Profiles of cognitive decline}

A 3 (Group) $\times 9$ (Time) ANOVA was run on MMSE total scores, revealing as significant the main 
Table 3

Demographic, cognitive, and functional characteristics of groups (mean $\pm \mathrm{SD}$ )

\begin{tabular}{|c|c|c|c|c|c|}
\hline & Sample & $\begin{array}{c}\text { Slow } \\
\text { Decliners }\end{array}$ & $\begin{array}{l}\text { Intermediate } \\
\text { Decliners }\end{array}$ & $\begin{array}{c}\text { Fast } \\
\text { Decliners }\end{array}$ & ANOVA \\
\hline Age- $\mathrm{T}_{0}$ & $77.3 \pm 6.5$ & $77.1 \pm 6.3$ & $78.5 \pm 7.3$ & $77.4 \pm 6.9$ & n.s. \\
\hline Age of onset & $74.6 \pm 6.8$ & $74.5 \pm 6.6$ & $75.3 \pm 7.3$ & $74.8 \pm 7.3$ & n.s. \\
\hline Age $\mathrm{T}_{0}$ minus age of onset & $2.7 \pm 2.3$ & $2.6 \pm 2.2$ & $3.2 \pm 2.6$ & $2.6 \pm 2.6$ & n.s. \\
\hline Education (years) & $5.5 \pm 2.9$ & $5.6 \pm 3.1$ & $4.9 \pm 2.4$ & $5.5 \pm 3.5$ & n.s. \\
\hline \multicolumn{6}{|l|}{ MMSE } \\
\hline $\mathrm{T}_{0}$ & $18.4 \pm 4.5$ & $18.1 \pm 4.2$ & $19.2 \pm 5.6$ & $19.5 \pm 4.7$ & n.s. \\
\hline $\mathrm{T}_{48}$ & $14.4 \pm 5.4$ & $14.4 \pm 5.3$ & $13.3 \pm 6.4$ & $15.3 \pm 5.1$ & n.s. \\
\hline \multicolumn{6}{|l|}{ ADL } \\
\hline $\mathrm{T}_{0}$ & $4.9 \pm 1.4$ & $4.9 \pm 1.4$ & $5.2 \pm 1.4$ & $4.7 \pm 1.5$ & n.s. \\
\hline $\mathrm{T}_{48}$ & $2.9 \pm 1.5$ & $2.9 \pm 1.6$ & $2.1 \pm 1.2$ & $3.1 \pm 1.3$ & n.s. \\
\hline \multicolumn{6}{|l|}{ IADL } \\
\hline $\mathrm{T}_{0}$ & $3.9 \pm 2.3$ & $4.2 \pm 2.3$ & $4.2 \pm 2.3$ & $3.2 \pm 2.2$ & $\begin{array}{c}\mathrm{F}_{[2,318]}=4.23, p<0.05 \\
\eta^{2}=0.026\end{array}$ \\
\hline \multirow[t]{2}{*}{$\mathrm{T}_{48}$} & $1.2 \pm 1.5$ & $1.4 \pm 1.6$ & $0.53 \pm 0.9$ & $0.75 \pm 0.7$ & $\begin{array}{c}\mathrm{F}_{[2,152]}=3.13, p<0.05 \\
\eta^{2}=0.039\end{array}$ \\
\hline & & & & & Chi-square test \\
\hline Gender & $254 \mathrm{~F}, 70 \mathrm{M}$ & $183 \mathrm{~F}, 42 \mathrm{M}$ & $25 \mathrm{~F}, 12 \mathrm{M}$ & $46 \mathrm{~F}, 15 \mathrm{M}$ & n.s. \\
\hline Familiar history of dementia & $\begin{array}{c}50 / 164 \\
(160 \text { m.d. })\end{array}$ & $\begin{array}{c}37 / 124 \\
\text { (101 m.d.) }\end{array}$ & $\begin{array}{c}3 / 15 \\
(22 \text { m.d. })\end{array}$ & $\begin{array}{c}10 / 25 \\
(37 \text { m.d.) }\end{array}$ & n.s. \\
\hline \multicolumn{6}{|l|}{$\mathrm{AChEI} / \mathrm{memantine}$ treatment } \\
\hline $\mathrm{T}_{0}$ & $43 / 324$ & $27 / 225$ & $2 / 37$ & $14 / 62$ & n.s. \\
\hline $\mathrm{T}_{48}$ & $\begin{array}{l}135 / 154 \\
(2 \text { m.d. })\end{array}$ & $\begin{array}{l}105 / 119 \\
(2 \text { m.d. })\end{array}$ & $13 / 15$ & $17 / 20$ & n.s. \\
\hline \multicolumn{6}{|l|}{ Antipsychotic treatment } \\
\hline $\mathrm{T}_{0}$ & $4 / 324$ & $2 / 225$ & $1 / 37$ & $1 / 62$ & n.s. \\
\hline $\mathrm{T}_{48}$ & $30 / 156$ & $23 / 121$ & $7 / 15$ & $0 / 20$ & $\chi^{2}=12.03, p<0.01 ; C=0.268$ \\
\hline
\end{tabular}

SD, standard deviation; $\mathrm{T}_{0}$, baseline evaluation; $\mathrm{T}_{48}$, evaluation at 48 months; MMSE, Mini-Mental State Examination; ADL, Activities of Daily Living; IADL, Instrumental Activities of Daily Living; F, females, M, males; m.d., missing data; sig., significance; n.s., no significant differences; AChEI, acetylcholinesterase inhibitors treatment.

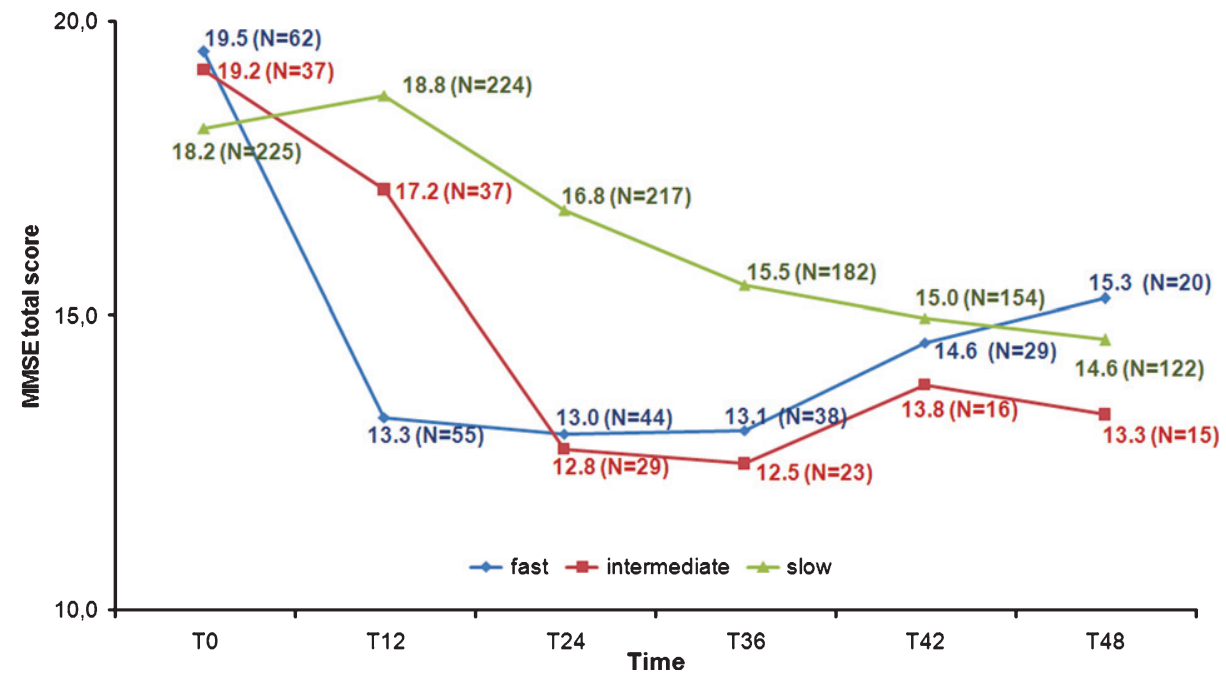

Fig. 2. Mini-Mental State Examination (MMSE) total scores from T0 to T48.

effect of Time $\left(\mathrm{F}_{[8,108]}=49.75, p<0.001, \chi^{2}=0.31\right)$ and the Group $\times$ Time interaction $\left(\mathrm{F}_{[13,108]}=8.21\right.$, $p<0.001, \chi^{2}=0.13$ ), but not the main effect of Group (see Fig. 2).
Post-hoc tests (Bonferroni) confirmed the expected similarity of the groups at $\mathrm{T} 0$; at $\mathrm{T} 12$ emerged, coherently with the clustering criterion, differences in the FD scores versus ID (means differences 


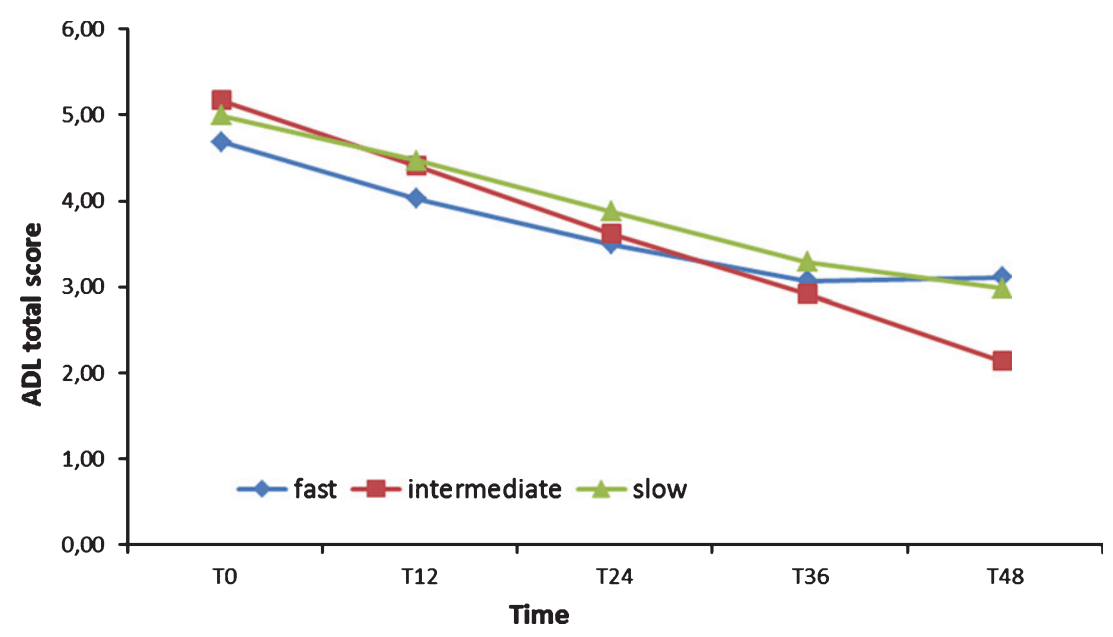

Fig. 3. Activities of Daily Living (ADL) total scores from T0 to T48.

$95 \% \mathrm{CI}=-6.62--1.11)$ and SD ones (means difference $95 \% \mathrm{CI}=-7.16--3.53)$, whereas ID and SD scores were not dissimilar. At T24, FD and ID resulted no more significantly different, while their MMSE was lower than SD (means difference $95 \% \mathrm{CI}=-5.94--1.55$ and $=-6.64--1.35$, respec tively). Three years after the baseline the pattern of scores remained stable, but the groups differences were only slightly detectable (means difference 95\%CI: FD versus $\mathrm{SDs}=-4.78-0.12$; ID versus $\mathrm{SD}=-5.84-0.06)$. At the end of the 4-year followup, all groups' MMSE scores were comparable.

The significant interaction depicted a dissimilar pattern of cognitive decline into our groups, as confirmed by the polynomial trend analysis. The FD trend showed, indeed, as significant above all the cubic $\left(\mathrm{F}_{[1,11]}=32.24, p<0.001\right)$ and then the linear component $\left(\mathrm{F}_{[1,11]}=15.96, p<0.01\right)$, that was, instead, the only component to be significant into the ID decline $\left(\mathrm{F}_{[1,11]}=76.11, p<0.001\right)$. The SD trend was explained mainly by linear $\left(\mathrm{F}_{[1,11]}=58.19\right.$, $p<0.001)$, and quadratic $\left(\mathrm{F}_{[1,11]}=38.19, p<0.001\right)$ components.

Paired $t$-test (Bonferroni correction was applied for multiple comparisons) showed that the FD and ID baseline MMSE total scores were significantly $(p<0.01)$ the highest ones. FD and ID scores at $\mathrm{T}_{6}$ and $\mathrm{T}_{18}$ were significantly higher $(p<0.01)$ than all the following surveys (FD $\mathrm{T}_{12}$ score was higher only than $\mathrm{T}_{30}$ and $\mathrm{T}_{36}$ grades, $p<0.05$ ): two years after the baseline, the MMSE total scores were no more different. Conversely, in all the paired comparisons from $\mathrm{T}_{12}$ to $\mathrm{T}_{48}$ each $\mathrm{SD}$ total score resulted significantly greater $(p<0.01)$ than every further one.
The decline of the single MMSE sub-items scores was congruent with the total score pattern, except for delayed recall and constructional praxis, not significantly different between groups along the time.

\section{Profiles of functional decline}

Two 3 (Group) $\times 9$ (Time) ANOVA were run on ADL and IADL scores: both showed as significant only the main effect of Time (respectively: $\mathrm{F}_{[8,108]}=29.83, p<0.001, \chi^{2}=0.33 ; \mathrm{F}_{[8,108]}=30.81$, $\left.p<0.001, \chi^{2}=0.34\right)$. Post hoc tests (Bonferroni) confirmed that FD, ID, and SD ADL scores did not differ, from $\mathrm{T}_{0}$ forward (see Fig. 3). The IADL of the FD group, instead, was significantly lower $(p<0.01)$ than the IADL of the SD group from $\mathrm{T}_{0}$ to two years after the baseline (see Fig. 4) and lower than the ID score at $\mathrm{T}_{0}, \mathrm{~T}_{6}$, and $\mathrm{T}_{30}$. Finally, ID IADL was inferior to the SD scores only at $\mathrm{T}_{18}$.

\section{Subject dropout}

To complete our analysis, we also aimed to explore the withdrawal of participants along the four years of the survey, focusing on the dissimilar rate of dropouts between FD, ID, and SD.

Dropout individuals were, in most cases, patients without applicable MMSE scores (MMSE <3/30) or with the presence of severe behavioral and psychological symptoms of dementia, which were continued to be treated in our clinic.

At $\mathrm{T}_{48}$, the whole sample included 156 participants (survivors), i.e., $48.5 \%$ of the patients who had been enrolled at $\mathrm{T}_{0}, 21.2 \%$ males and $28.8 \%$ females (these 


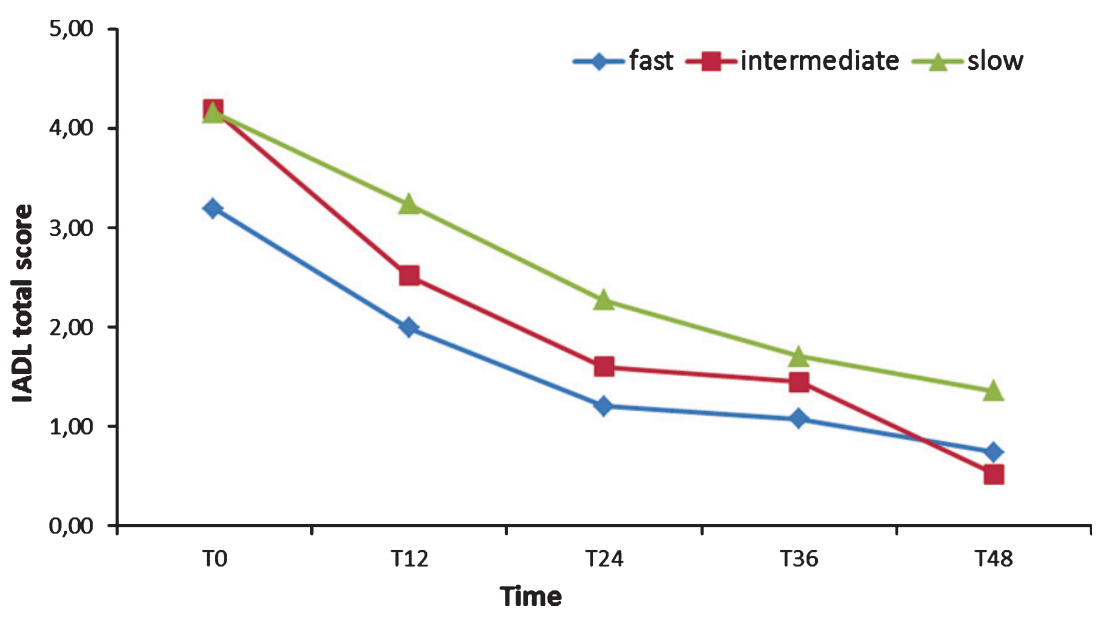

Fig. 4. Instrumental Activities of Daily Living (IADL) total scores from T0 to T48.

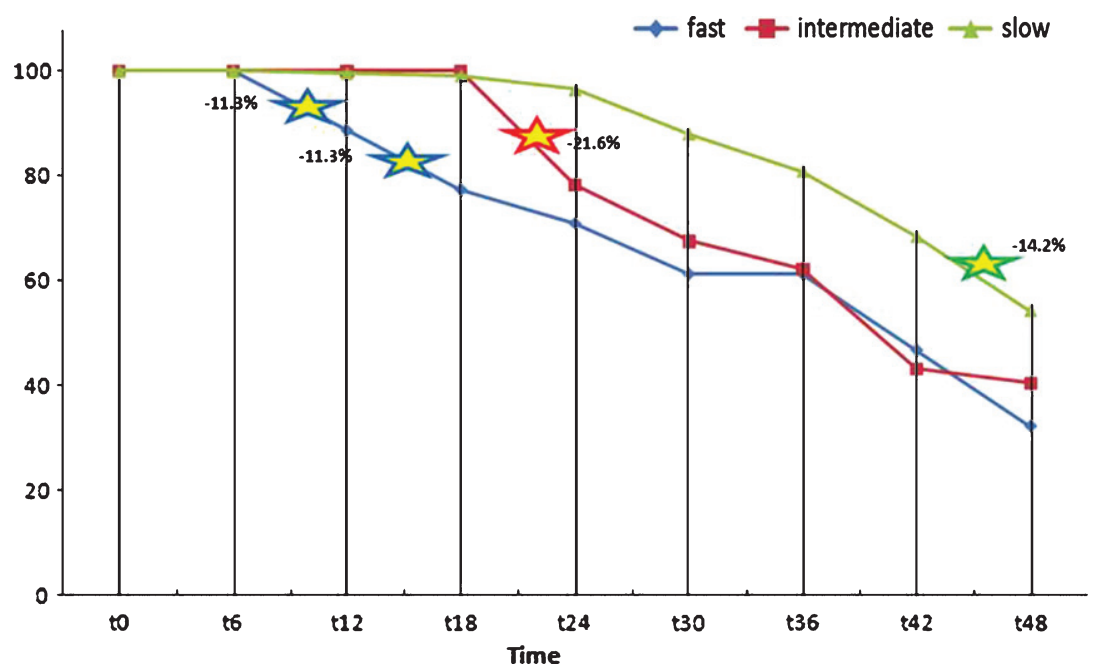

Fig. 5. Patient withdrawals from $\mathrm{T}_{0}$ to $\mathrm{T}_{48}$.

percentages were homogeneous to baseline). Both at $\mathrm{T}_{12}$ and $\mathrm{T}_{18}$, only 8 individuals $(2.5 \%)$ quit, but the percentage of dropouts increased from $\mathrm{T}_{24}$ forward: $5.6 \%, 9 \%, 5.6 \%, 13.6 \%$, and, finally, $13 \%$.

Splitting the whole sample into FDs, IDs, and SDs: four years after baseline, FDs had lost $67 \%$ of their participants (survivors $=20$ ), IDs $59.5 \%$ (survivors $=15$ ), and SDs less than $50 \%$ (survivors $=121$, i.e., $53.8 \%$ of $\mathrm{T}_{0}$ group). The strongest rates of dropout seemed to coincide, at the beginning of the survey, with the period that immediately followed the MMSE total score maximum decrease, in accordance with the grouping criterion: $\mathrm{T}_{6}-\mathrm{T}_{12}=-11.5 \%$ and $\mathrm{T}_{12}-\mathrm{T}_{18}=-11.5 \%$ for FDs, $\mathrm{T}_{18}-\mathrm{T}_{24}=-21.6 \%$ for
SDs. From $\mathrm{T}_{36}$ forward, all groups showed another marked downshift (see Fig. 5).

ROC curve analysis showed that a $\mathrm{T}_{12}$ MMSE score $\geq 14$ could correctly predict the persistence of FDs into their own group at $\mathrm{T}_{48}$ (Area Under Curve $=0.861, \quad \mathrm{SE}=0.051, \quad 95 \% \mathrm{CI}=0.761-0.962$; sensibility $=0.778,1$-specificity $=0.229$ ).

No significant differences were found in demographic characteristics or ADL and IADL scores (see Table 4) between FDs survivors $(n=20,70 \%$ females) and dropouts $(n=42)$.

Univariate ANOVAs showed, from $\mathrm{T}_{0}$ to $\mathrm{T}_{42}$, that survivors' MMSE total scores were significantly higher (see Fig. 6). 
Table 4

Demographic, cognitive, and functional characteristics of fast decline (FD) survivors and FD dropouts(mean \pm SD)

\begin{tabular}{lccc}
\hline & FD survivors & FD dropouts & ANOVA \\
\hline Age- $\mathrm{T}_{0}$ & $76.9 \pm 6.5$ & $77.6 \pm 7.2$ & n.s. \\
Age of onset & $74.5 \pm 7.2$ & $74.6 \pm 7.4$ & n.s. \\
Age $\mathrm{T}_{0}$-age of onset & $2.3 \pm 1.8$ & $2.8 \pm 2.9$ & n.s. \\
Education (years) & $6.3 \pm 4.2$ & $5.2 \pm 3.1$ & n.s. \\
$\mathrm{MMSE}$ & $22.8 \pm 2.5$ & $17.9 \pm 4.5$ & $\mathrm{~F}_{[1,60]}=19.2 p<0.001, \eta^{2}=0.243$ \\
$\mathrm{~T}_{0}$ & $16.4 \pm 3.8$ & $11.3 \pm 5.9$ & $\mathrm{~F}_{[1,23]}=6.82 p<0.05, \eta^{2}=0.229$ \\
$\mathrm{~T}_{42}$ & $5.0 \pm 1.3$ & $4.5 \pm 1.5$ & n.s. \\
$\mathrm{ADL}$ & $3.0 \pm 1.3$ & $2.0 \pm 1.7$ & n.s. \\
$\mathrm{T}_{0}$ & $3.9 \pm 1.9$ & $2.9 \pm 2.2$ & n.s. \\
$\mathrm{T}_{42}$ & $0.8 \pm 0.8$ & $1.0 \pm 1.7$ & n.s. \\
$\mathrm{IADL}_{\mathrm{T}}$ & & & Chi-square test \\
$\mathrm{T}_{0}$ & $6 \mathrm{M}, 14 \mathrm{~F}$ & $10 \mathrm{M}, 32 \mathrm{~F}$ & n.s. \\
$\mathrm{T}_{42}$ & $2 / 8(12 \mathrm{~m} . \mathrm{d}$. $)$ & $8 / 17(25 \mathrm{~m}$. d. $)$ & n.s. \\
\hline Gender & & & \\
Familiar history of dementia & & & \\
\hline
\end{tabular}

MMSE, Mini-Mental State Examination; ADL, Activities of Daily Living; IADL, Instrumental Activities of Daily Living.

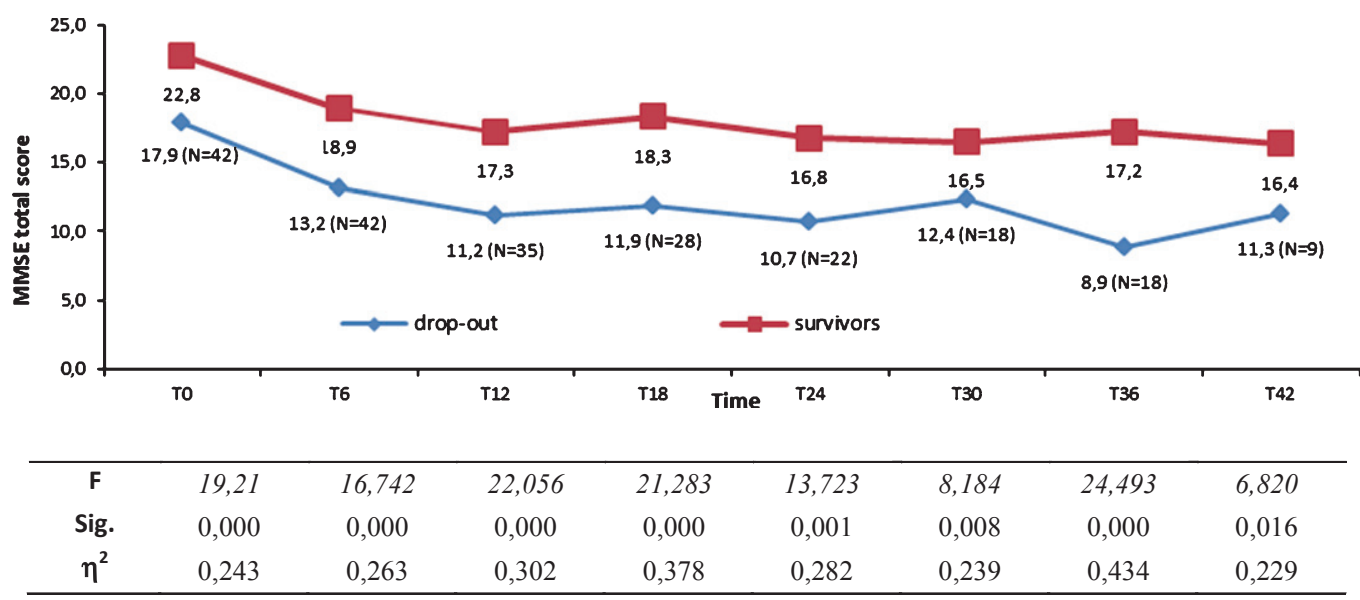

Fig. 6. Mini-Mental State Examination (MMSE) total scores of fast decliner (FD) survivors $(\mathrm{N}=20)$ and $\mathrm{FD}$ dropouts from $\mathrm{T}_{0}$ to $\mathrm{T}_{42}$ as indicated by progressively decrease number of subjects.

\section{DISCUSSION}

The aim of the present study was to describe the evolution of $\mathrm{AD}$ patients with the attempt to better define the current opinion of rapidly progressive evolution, by means of a long observation interval of four years.

It is of common clinical experience to have AD individuals with a rapid decline within one year and on the other hand, subjects with the same fast evolution within 12 months followed by fluctuations in cognitive performance and loss of five points in a longer interval of time that we arbitrarily decide to include within the first 18 months. Therefore, using the cut-off of 5 points, we looked for patients with a rapid decline within 12 or 18 months from baseline to evaluate the clinical utility of an early stratification. The choice of the 5-point loss was made in agreement with the literature and with the observation that this value is indicative of a clinically relevant progression of the disease, not influenced by the intrinsic limits of test reliability $[39,40]$ and in accordance with the mean rate of MMSE decline of 2 to 4 points/year $[1,20]$.

Our population did not differ in terms of age at baseline, age at onset, sex, education, or familiar history of dementia among FD, ID, and SD.

At variance with many previous studies, in our sample the speed of decline did not correlate with 
the age of onset of $\mathrm{AD}$ and the educational level of participants.

To minimize the bias due to the effect of possible different disease stages, we compared years between disease onset and baseline visit, finding no differences among the three groups. None of the comorbidities analyzed appeared to be more frequent in FD and ID. In the current study, as previously reported $[41,42]$, we found no relationship between the presence of vascular risk factors (smoking, hypertension, diabetes, and dyslipidemia), alcohol assumption, and other diseases (folic acid or cobalamine deficit, hypothyroidism, anemia, cardiac, renal or hepatic failure, cerebral stroke, myocardial infarction, atrial fibrillation, and epilepsy) and rapid cognitive decline. These results seem to confirm the hypothesis that some risk factors promoting the onset of $\mathrm{AD}$ are not sufficient in modulating the speed of decline.

Some methodological limits and procedural differences may in part account for the inconsistent results on the correlation between comorbidities and rates of decline. Much of the evidence derives from studies that were originally designed and conducted to investigate other conditions. Furthermore, when we consider the association between a comorbidity and its potential role in accelerating cognitive decline, many other variables and more complex mechanism may play a decisive role (for example, hypertension is a variable factor based on age of onset, therapy compliance, different antihypertensive agents, different gold standard pressure target related to age, etc.) [43]. Further randomized controlled trials focused on correlation between a single or a cluster of comorbidities and rates of decline are needed to better investigate the existence of clinical predictors.

Despite a 5-point loss or more on the MMSE in the first year, FD show a higher, although not statistically significant, score on the MMSE compared to the remaining groups at the end of the observation period. The threshold of decline, established as 5point MMSE decrease during the first 12 or 18 months of clinical observation was not significantly associated with worse cognitive performance at the end of the 4-year follow-up. Our early stratification based on the MMSE failed to intercept more impaired patients at the end of a long period of observation. It is important to note that if we had used a shorter follow-up as usually reported in the literature (i.e. 2 years), FD and ID were significantly more compromised than the SD. Only a long follow-up allowed us to reveal the tendency to converge and the absence of cognitive differences between the three groups. By shortening the period of observation and therefore the time from baseline, the results are likely to be more biased by the initial categorization.

Consistent with the cognitive profile, the functional decline, as indicated by ADL and IADL score, is similar between groups at the end of the 4-year follow-up. Additionally, the results are biased with a short period of observation with FD appearing worse than SD, suggesting the need for a prolonged period of observation as a more reliable measure of the clinical evolution of these patients.

To avoid any possible misinterpretations derived from bias selection, we also studied the dropout individuals, finding a homogeneous distribution of dropout patients in the three groups thus ruling out the possibility of a selection bias. Another interesting aspect of the dropout group was that the maximum decrease in cognitive performances measured by MMSE coincides with the last visit before dropout, thus suggesting that a significant loss on MMSE seems to be a risk for dropout. However, many patients classified as FD escape to a rapid decline, reaching the end of follow-up. Despite a significant loss on MMSE in the first 12 months, the FD who score $>14 / 30$ on MMSE at the first-year visit have a good chance of still being active and testable at the end of the 4 years (FD MMSE $\mathrm{T}_{48} 15.3 \pm 5.1$ ).

Some limitations deserve mention. People included in this study attended a third level outpatient clinic focused on cognitive disorders and might not be representative of the general population. Secondly, the study is retrospective and not autopsyverified. Third, data relating the apolipoprotein profile are lacking, thus avoiding any possible correlation on biological determinants of the clinical profile. Lastly, even though our sample represents a natural history of a real-world population referred to a single center with a starting size of more than 450 AD subjects, results should be interpreted with caution due to the small final sample of FD survivors.

In conclusion, despite the above-mentioned limitations, we have demonstrated that by extending the observation over a longer time interval than currently reported in the literature, the definition of "fast decliner" may change. Although cognitive decline is heterogeneous among patients with $\mathrm{AD}$, our results showed that the presence of a significant loss on MMSE in the first year does not help to predict a rapid cognitive impairment and a poor prognosis, but only with a longer follow-up it is possible to reject the current opinion of "fast decliners". Gathering other 
predictors of cognitive decline, such as genetic, morphological, and functional neuroimaging data, will help to shed some light on the different rate of decline in subjects with $\mathrm{AD}$.

\section{DISCLOSURE STATEMENT}

Authors' disclosures available online (http://j-alz. com/manuscript-disclosures/16-1264r1).

\section{REFERENCES}

[1] Morris JC, Edland S, Clark C, Galasko D, Koss E, Mohs R, van Belle G, Fillenbaum G, Heyman A (1993) The consortium to establish a registry for Alzheimer's disease (CERAD). Part IV. Rates of cognitive change in the longitudinal assessment of probable Alzheimer's disease. Neurology 43, 2457-2465.

[2] Schmidt C, Haik S, Satoh K, Rábano A, Martinez-Martin P, Roeber S, Brandel JP, Calero-Lara M, de Pedro-Cuesta J, Laplanche JL, Hauw JJ, Kretzschmar H, Zerr I (2012) Rapidly progressive Alzheimer disease: A multicenter update. J Alzheimers Dis 30, 751-756.

[3] Abellan van Kan G, Rolland Y, Nourhashémi F, Coley N, Andrieu S, Vellas B (2009) Cardiovascular disease risk factors and progression of Alzheimer's disease. Dement Geriatr Cogn Disord 27, 240-246.

[4] Helzner EP, Luchsinger JA, Scarmeas N, Cosentino S, Brickman AM, Glymour MM, Stern Y (2009) Contribution of vascular risk factors to the progression in Alzheimer's disease. Arch Neurol 66, 343-348.

[5] Roselli F, Tartaglione B, Federico F, Lepore V, Defazio G, Livrea P (2009) Rate of MMSE score change in Alzheimer's disease: Influence of education and vascular risk factors. Clin Neurol Neurosurg 111, 327-330.

[6] Dominguez RO, Marschoff ER, Gonzalez SE, Repetto MG, Serra JA (2012) Type 2 diabetes and/or its treatment leads to less cognitive impairment in Alzheimer's disease patients. Diabetes Res Clin Pract 98, 68-74.

[7] Ravona-Springer R, Luo X, Schmeidler J, Wysocki M, Lesser G, Rapp M, Dahlman K, Grossman H, Haroutunian V, Schnaider Beeri M (2010) Diabetes is associated with increased rate of cognitive decline in questionably demented elderly. Dement Geriatr Cogn Disord 29, 68-74.

[8] Sanz C, Andrieu S, Sinclair A, Hanaire H, Vellas B, REAL.FR Study Group (2009) Diabetes is associated with a slower rate of cognitive decline in Alzheimer's disease. Neurology 73, 1359-1366.

[9] Musicco M, Palmer K, Salamone G, Lupo F, Perri R, Mosti S, Spalletta G, di Iulio F, Pettenati C, Cravello L, Caltagirone C (2009) Predictors of progression of cognitive decline in Alzheimer's disease: The role of vascular and sociodemographic factors. J Neurol 256, 1288-1295.

[10] Musicco M, Salamone G, Caltagirone C, Cravello L, Fadda L, Lupo F, Mosti S, Perri R, Palmer K (2010) Neuropsychological predictors of rapidly progressing patients with Alzheimer's disease. Dement Geriatr Cogn Disord 30, 219228.

[11] Marra C, Silveri MC, Gainotti G (2000) Predictors of cognitive decline in the early stage of probable Alzheimer's disease. Dement Geriatr Cogn Disord 11, 212-218.
[12] Boller F, Becker JT, Holland AL, Forbes MM, Hood PC, McGonigle-Gibson KL (1991) Predictors of decline in Alzheimer's disease. Cortex 27, 9-17.

[13] Nyth AL, Gottfries C, Blennow K, Bråne G, Wallin A (1991) Heterogeneity of the course of Alzheimer's disease: A differentiation of subgroups. Dement Geriatr Cogn Disord 2, 18-24.

[14] Kinkingnéhun S, Sarazin M, Lehéricy S, Guichart-Gomez E, Hergueta T, Dubois B (2008) VBM anticipates the rate of progression of Alzheimer disease: A 3-year longitudinal study. Neurology 70, 2201-2211.

[15] Drachman DA, O’Donnell BF, Lew RA, Swearer JM (1990) The prognosis in Alzheimer's disease. 'How far' rather than 'how fast' best predicts the course. Arch Neurol 47, 851-856.

[16] Stern RG, Mohs RC, Davidson M, Schmeidler J, Silverman J, Kramer-Ginsberg E, Searcey T, Bierer L, Davis KL (1994) A longitudinal study of Alzheimer's disease: Measurement, rate, and predictors of cognitive deterioration. $\mathrm{Am}$ J Psychiatry 151, 390-396.

[17] Burns A, Jacoby R, Levy R (1991) Progression of cognitive impairment in Alzheimer's disease. J Am Geriatr Soc 39, 39-45.

[18] Adeghate E, Donáth T, Adem A (2013) Alzheimer disease and diabetes mellitus: Do they have anything in common? Curr Alzheimer Res 10, 609-617.

[19] Sims-Robinson C, Kim B, Rosko A, Feldman EL (2010) How does diabetes accelerate. Alzheimer disease pathology? Nat Rev Neurol 6, 551-559.

[20] Doody RS, Massman P, Dunn JK (2001) A method for estimating progression rates in Alzheimer disease. Arch Neurol 58, 449-454.

[21] Sona A, Zhang P, Ames D, Bush AI, Lautenschlager NT, Martins RN, Masters CL, Rowe CC, Szoeke C, Taddei K, Ellis KA; AIBL Research Group (2012) Predictors of rapid cognitive decline in Alzheimer's disease: Results from the Australian imaging, biomarkers and lifestyle (AIBL) study of ageing. Int Psychogeriatr 24, 197-204.

[22] Carcaillon L, Pérès K, Péré JJ, Helmer C, Orgogozo JM, Dartigues JF (2007) Fast cognitive decline at the time of dementia diagnosis: A major prognostic factor for survival in the community. Dement Geriatr Cogn Disord 23, 439445.

[23] Buccione I, Perri R, Carlesimo GA, Fadda L, Serra L, Scalmana S, Caltagirone C (2007) Cognitive and behavioural predictors of progression rates in Alzheimer's disease. Eur J Neurol 14, 440-446.

[24] O'Hara R, Thompson JM, Kraemer HC, Fenn C, Taylor JL, Ross L, Yesavage JA, Bailey AM, Tinklenberg JR (2002) Which Alzheimer patients are at risk for rapid cognitive decline? J Geriatr Psychiatry Neurol 15, 233-238.

[25] Wilkosz PA, Seltman HJ, Devlin B, Weamer EA, Lopez OL, DeKosky ST, Sweet RA (2010) Trajectories of cognitive decline in Alzheimer's disease. Int Psychogeriatr 22, 281290.

[26] Palmer K, Lupo F, Perri R, Salamone G, Fadda L, Caltagirone C, Musicco M, Cravello L (2011) Predicting disease progression in Alzheimer's disease: The role of neuropsychiatric syndromes on functional and cognitive decline. $J$ Alzheimers Dis 24, 35-45.

[27] Dumont C, Gillette-Guyonnet S, Andrieu S, Cantet C, Ousset PJ, Vellas B (2003) Rapid loss of the Mini Mental State Examination: REAL.FR study. Rev Med Interne 24(Suppl 3), 345s-350s.

[28] Mayeux R, Stern Y, Spanton S (1985) Heterogeneity in dementia of the Alzheimer type. Neurology 35, 453. 
[29] Lo RY, Jagust WJ (2013) Effect of cognitive reserve markers on Alzheimer pathologic progression. Alzheimer Dis Assoc Disord 27, 343-350.

[30] Bellelli G, Lucchi E, Minicuci N, Rozzini L, Bianchetti A, Padovani A, Trabucchi M (2005) Results of a multi-level therapeutic approach for Alzheimer's disease subjects in the "real world" (CRONOS project): A 36-week follow-up study. Aging Clin Exp Res 17, 54-61.

[31] Leoutsakos JM, Muthen BO, Breitner JC, Lyketsos CG, ADAPT Research Team (2012) Effects of non-steroidal anti-inflammatory drug treatments on cognitive decline vary by phase of pre-clinical Alzheimer disease: Findings from the randomized controlled Alzheimer's Disease Anti-inflammatory Prevention Trial. Int J Geriatr Psychiatry 27, 364-374.

[32] Wainaina MN, Chen Z, Zhong C (2014) Environmental factors in the development and progression of late-onset Alzheimer's disease. Neurosci Bull 30, 253-270.

[33] Briones TL (2006) Environment, physical activity, and neurogenesis: Implications for prevention and treatment of Alzheimer's disease. Curr Alzheimer Res 3, 49-54.

[34] Heyman A, Peterson B, Fillenbaum G, Pieper C (1997) Predictors of time to institutionalization of patients with Alzheimer's disease: The CERAD experience, part XVII. Neurology 48, 1304-1309.

[35] Brodaty H, Connors MH, Xu J, Woodward M, Ames D; PRIME study group (2014) Predictors of institutionalization in dementia: A three year longitudinal study. J Alzheimers Dis 40, 221-226.

[36] American Psychiatric Association (1994) Diagnostic and statistical manual of mental disorders (DSM-IV-TR) 4th edn. American Psychiatric Association, Washington, DC.

[37] Dubois B, Feldman HH, Jacova C, Dekosky ST, BarbergerGateau P, Cummings J, Delacourte A, Galasko D, Gauthier S, Jicha G, Meguro K, O'brien J, Pasquier F, Robert P, Rossor M, Salloway S, Stern Y, Visser PJ, Scheltens P (2007) Research criteria for the diagnosis of Alzheimer's disease: Revising the NINCDS-ADRDA criteria. Lancet Neurol 6, 734-746.

[38] Folstein MF, Folstein SE, McHugh PR (1975) 'Mini Mental State'. A practical method for grading the cognitive state of patients for the clinician. J Psychiatr Res 12, 189-198.

[39] Lawton MP, Brody EM (1969) Assessment of older people: Self maintaining and instrumental activities of daily living. Gerontologist 9, 179-186.

[40] Ruitenberg A, Kalmijn S, de Ridder MA, Redekop WK, van Harskamp F, Hofman A, Launer LJ, Breteler MM (2001) Prognosis of Alzheimer's disease: The Rotterdam Study. Neuroepidemiology 20, 188-195.

[41] Blom K, Emmelot-Vonk MH, Koek HD (2013) The influence of vascular risk factors on cognitive decline in patients with dementia: A systematic review. Maturitas 76, 113-117.

[42] Blom K, Vaartjes I, Peters SA, Koek HL (2014) The influence of vascular risk factors on cognitive decline in patients with Alzheimer's disease. Maturitas 79, 96-99.

[43] Meng XF, Yu JT, Wang HF, Tan MS, Wang C, Tan CC, Tan L (2014) Midlife vascular risk factors and the risk of Alzheimer's disease: A systematic review and metaanalysis. J Alzheimers Dis 42, 1295-1310.

[44] Sakurai H, Hanyu H, Sato T, Kanetaka H, Shimizu S, Hirao K, Kikukawa M, Iwamoto T (2011) Vascular risk factors and progression in Alzheimer's disease. Geriatr Gerontol Int 11, 211-214.
[45] Li J, Zhang M, Xu ZQ, Gao CY, Fang CQ, Deng J, Yan JC, Wang YJ, Zhou HD (2010) Vascular risk aggravates the progression of Alzheimer's disease in a Chinese cohort. J Alzheimers Dis 20, 491-500.

[46] Li L, Cao D, Desmond R, Rahman A, Lah JJ, Levey AI, Zamrini E. (2008) Cognitive performance and plasma levels of homo-cysteine, vitamin B12, folate and lipids in patients with Alzheimer's disease. Dement Geriatr Cogn Disord 26, 384-390.

[47] Ciobica A, Padurariu M, Bild W, Stefanescu C (2011) Cardiovascular risk factors as potential markers for mild cognitive impairment and Alzheimer's disease. Psychiatr Danub 23, 340-346.

[48] Mielke MM, Rosenberg PB, Tschanz J, Cook L, Corcoran C, Hayden KM, Norton M, Rabins PV, Green RC, WelshBohmer KA, Breitner JC, Munger R, Lyketsos CG (2007) Vascular factors predict rate of progression in Alzheimer's disease. Neurology 69, 1850-1858.

[49] Chaves ML, Camozzato AL, Kohler C, Kaye J (2010) Predictors of the progression of dementia severity in brazilian patients with Alzheimer's disease and vascular dementia. Int J Alzheimers Dis 2010, pii: 673581.

[50] Bhargava D, Weiner MF, Hynan LS, Diaz-Arrastia R, Lipton AM (2006) Vascular disease and risk factors, rate of progression, and survival in Alzheimer's disease. J Geriatr Psychiatry Neurol 19, 78-82.

[51] Van Bruchem-Visser RL, Mattace-Raso FU, van der Cammen TJ (2009) High systolic and pulse pressure levels are associated with better cognitive performance in patients with probable Alzheimer's disease: A cross-sectional observational study in a geriatric outpatient population. Dement Geriatr Cogn Disord 28, 320-324.

[52] Regan C, Katona C, Walker Z, Hooper J, Donovan J, Livingston $\mathrm{G}$ (2006) Relation-ship of vascular risk to the progression of Alzheimer's disease. Neurology 67, 1357-1362.

[53] Teri L, McCurry SM, Edland SD, Kukull WA, Larson EB (1995) Cognitive decline in Alzheimer's disease: A longitudinal investigation of risk factors for accelerated decline. J Gerontol A Biol Sci Med Sci 50A, M49-55.

[54] Scarmeas N, Albert SM, Manly JJ, Stern Y (2006) Education and rates of cognitive decline in incident Alzheimer's disease. J Neurol Neurosurg Psychiatry 77, 308-316.

[55] Pavlik VN, Doody RS, Massman PJ, Chan W (2006) Influence of premorbid IQ and education on progression of Alzheimer's disease. Dement Geriatr Cogn Disord 22, 367-377.

[56] Mungas D, Reed BR, Ellis WG, Jagust WJ (2001) The effects of age on rate of progression of Alzheimer disease and dementia with associated cerebrovascular disease. Arch Neurol 58, 1243-1247.

[57] Haupt M, Kurz A, Pollmann S, Romero B (1992) Symptom severity and symptom progression in Alzheimer's diseasecomparison between two cases with early and late onset. Nervenarzt 63, 561-565.

[58] Mangone CA (2004) Clinical heterogeneity of Alzheimer's disease. Different clinical profiles can predict the progression rate. Rev Neurol 38, 675-681.

[59] Starkstein SE, Jorge R, Mizrahi R, Robinson RG (2006) A prospective longitudinal study of apathy in Alzheimer's disease. J Neurol Neurosurg Psychiatry 77, 8-11.

[60] Ito K, Ahadieh S, Corrigan B, French J, Fullerton T, Tensfeldt T; Alzheimer's Disease Working Group (2010) Disease progression meta-analysis model in Alzheimer's disease. Alzheimers Dement 6, 39-53. 
[61] Mann UM, Mohr E, Gearing M, Chase TN (1992) Heterogeneity in Alzheimer's disease: Progression rate segregated by distinct neuropsychological and cerebral metabolic profiles. J Neurol Neurosurg Psychiatry 55, 956-959.

[62] Smith MZ, Esiri MM, Barnetson L, King E, Nagy Z (2001) Constructional apraxia in Alzheimer's disease: Association with occipital lobe pathology and accelerated cognitive decline. Dement Geriatr Cogn Disord 12, 281-288

[63] Schmidt C, Redyk K, Meissner B, Krack L, von Ahsen N, Roeber S, Kretzschmar H, Zerr I (2010) Clinical features of rapidly progressive Alzheimer's disease. Dement Geriatr Cogn Disord 29, 371-378.

[64] Scarmeas N, Albert M, Brandt J, Blacker D, Hadjigeorgiou G, Papadimitriou A, Dubois B, Sarazin M, Wegesin D, Marder K, Bell K, Honig L, Stern Y (2005) Motor signs predict poor outcomes in Alzheimer disease. Neurology 64, 1696-1703.

[65] Cosentino S, Scarmeas N, Helzner E, Glymour MM, Brandt J, Albert M, Blacker D, Stern Y (2008) APOE epsilon 4 allele predicts faster cognitive decline in mild Alzheimer disease. Neurology 70(19 Pt 2), 1842-1849.

[66] Craft S, Teri L, Edland SD, Kukull WA, Schellenberg G, McCormick WC, Bowen JD, Larson EB (1998) Accelerated decline in apolipoprotein E-epsilon4 homozygotes with Alzheimer's disease. Neurology 51, 149-153.

[67] Van der Viles AE, Koedam EL, Pijnenburg YA, Twisk JW, Scheltens P, van der Flier WM (2009) Most rapid cognitive decline in APOE epsilon4 negative Alzheimer's disease with early onset. Psychol Med 39, 1907-1911.

[68] Soto ME, (a), Andrieu S, Cantet C, Reynish E, Ousset PJ, Arbus C, Gillette-Guyonnet S, Nourhashémi F, Vellas B; REAL.FR group (2008) Predictive value of rapid decline in mini mental state examination in clinical practice for prognosis in Alzheimer's disease. Dement Geriatr Cogn Disord 26, 109-116.

[69] Soto ME, Gillette-Guyonnet S, Vellas B (2005) Rapid cognitive decline: Searching for a definition and predictive factors among elderly with Alzheimer's disease. Nutr Health Aging 9, 158-161.

[70] Soto ME, Andrieu S, Arbus C, Ceccaldi M, Couratier P, Dantoine T, Dartigues JF, Gillette-Guyonnet S, Nourhashemi F, Ousset PJ, Poncet M, Portet F, Touchon J, Vellas B (2008) Rapid cognitive decline in Alzheimer's disease. Consensus paper. J Nutr Health Aging 12, 703-713.

[71] Schmidt C, Wollf M, Weitz M, Bartlau T, Korth C, Zerr I (2011) Rapidly progressive Alzheimer disease. Arch Neurol 68, 1124-1130. 